\title{
SIFAT FISIK, KIMIA DAN ORGANOLEPTIK PERMEN JELLY TOMAT DENGAN VARIASI JENIS GULA DAN BAHAN PEMBENTUK GEL
}

\author{
Catur Budi Handayani, Sri Hartati, Afriyanti \\ 1) Program Studi Teknologi Hasil Pertanian, Fakultas Pertanian, Universitas Veteran Bangun Nusantara \\ Jl. Letjen Sujono Humardani No. 1, Sukoharjo Tel. 0271-593156, Fax 0271-591065, \\ Email: caturiazuli41@gmail.com
}

\begin{abstract}
ABSTRAK
Telah dilakukan penelitian tentang permen jelly tomat untuk mengetahui sifat fisik (kadar air), sifat kimia (kadar gula reduksi) dan sifat organoleptik (rasa, kesukaan) jely tomat dengan variasi jenis gula (glukosa, dekstrosa dan sukrosa) dan bahan pembentuk gel (agar-agar dan serbuk jelly) yang ditambahkan. Penelitian menggunakan rancangan faktorial. Hasil penelitian menunjukkan bahwa kadar air permen jelly tomat berkisar antara $7,4-10,03 \%$ dan tidak ada perbedaan nyata di antara semua perlakuan. Kadar gula reduksi berkisar antara $0.59-3,46 \%$ dan ada perbedaan nyata antara permen yang menggunakan dektrosa dengan jenis gula yang lain. Sifat organoleptik terhadap rasa menunjukkan bahwa permen jelly tomat yang paling disukai adalah permen yang dibuat menggunakan sukrosa dan agar dengan skor 3,03 (enak) dan yang paling tidak disukai adalah permen jelly dengan dekstrosa agar. Uji organoleptik terhadap kesukaan secara menyeluruh memperlihatkan bahwa permen yang paling disukai adalah permen yang dibuat dengan glukosa agar dan permen yang paling tidak disukai adalah permen yang dibuat dengan menggunakan dekstrosa agar.
\end{abstract}

Kata kunci : permen jelly tomat, gula, agar, bubuk jeli

\begin{abstract}
The purpose of this study was to determine the characteristics of the physical, chemical characteristic (reducing sugar content) and organoleptic characteristic (taste, preference) tomato jelly with various types of sugar (glucose, dextrose and sucros and gelling agents (agar and jelly powder) are added. The study used a factorial design. The results showed that the water content of the tomato jelly candy ranged from 7.4 to $10.03 \%$ and there was no significant difference between all treatments. The reducing sugar content ranged from 0.59 to $3.46 \%$ and there was a significant difference between candy using dextrose and other types of sugar. The organoleptic characteristic of taste showed that the most preferred tomato jelly candy was candy made using sucrose and agar with a score of 3.03 (delicious) and the least preferred was jelly candy with dextrose agar. The overall organoleptic test of liking showed that the most preferred candy was candy made with glucose agar and the least preferred candy was candy made using dextrose agar.
\end{abstract}

Keywords: tomato jelly candy, sugar, agar, jelly powder 


\section{PENDAHULUAN}

Tomat (Licopersicum esculentum Mill.) merupakan salah satu produk hortikultura yang berlimpah di pasar. Lahan tomat di Jawa Tengah pada tahun 2015 mencapai 4.371 ha dengan produksi mencapai 62. 928 ton. Produksi tomat tertinggi di Indonesia adalah provinsi Jawa Barat dengan luas areal panen mencapai 10.100 dengan jumlah produksi 298.445 ton (BPS dan Kementerian Pertanian $\mathrm{RI})$.

Tomat merupakan salah satu jenis sayuran buah yang dibutuhkan pada saat ini, baik dalam bentuk segar maupun olahan (industri). Sebagai buah segar, tomat merupakan sumber vitamin $A$ dan $C$ disamping mengandung sejumlah mineral yang dibutuhkan tubuh seperti Kalium, Fosfat dan Calsium (Buckle at.al. 1987)

Tomat mengandung zat likopen yang memberikan warna merah pada tomat. Likopen merupakan karotenoid yang bersifat antioksidan yang telah diketahui memiliki kemampuan mencegah terbentuknya sel yang tidak sehat (Novita, M. dkk. 2010)

Kandungan vitamin $\mathrm{C}$ dalam buah tomat relative cukup banyak sehingga dipercaya mempercepat kesembuhan luka, mencegah terjangkitnya penyakit skorbut, menghindarkan perdarahan dan pembuluh darah halus, dan membuat kulit bebas dari jerawat. Kandungan vitamin A pada tomat juga cukup tinggi bisa membantu penyembuhan buta malam (Winarno, FG. 2004)

Tomat juga digunakan sebagai sayuran dalam masakan, bumbu masak, bahan baku industri pangan maupun obat-obatan dan kosmetik. Karena masa panen buah tomat hanya 2 kali setahun, maka walaupun produksinya melimpah kadang suatu saat tidak banyak ada di pasar. Kelangkaan ini juga disebabkan karena buah tomah tidak tahan lama disimpan. Pada suhu ruang buah tomat hanya bertahan selama $3-4$ hari, sedangkan pada suhu refrigerator buah tomat bisa bertahan $1-2$ minggu saja. Pada saat musim panen sering kali terjadi ketimpangan antara jumlah yang tersedia dan permintaaan di pasar sehingga banyak buah tomat yang tidak termanfaatkan atau terjual dengan harga yang sangat murah. Pengolahan tomat untuk industri rumah tangga perlu digalakkan untuk memanfaatkan buah tomat yang melimpah terutama pada musim panen. Pengolahan yang baik diikuti dengan pengemasan yang benar akan menghasilkan produk olahan tomat yang baik dan umur simpan yang panjang. Salah satu unsur yang berpengaruh pada umur simpan adalah kadar air bahan pangan tersebut

Pengolahan buah tomat selama ini belum banyak variasi. Pemanfaatan buah tomat yang banyak dilakukan adalah dengan mengolahnya menjadi saos tomat (Handayani, C.B dkk. 2018). Produk inipun hanya mampu bertahan selama kurang lebih 2 tahun dengan cara pengolahan yang baik seperti pada industri besar.

Pengolahan tomat yang lain adalah manisan tomat. Manisan tomat kurang populer di masyarakat. Produk ini kurang diminati karena yang bisa digunakan adalah tomat dengan ukuran buah yang kecil. Tomat dengan ukuran yang besar dalam proses pengolahannya akan memakan waktu yang cukup lama agar gula meresap dan kering sampai ke dalam buah. Jelly kering tomat atau permen jelly tomat merupakan salah satu alternatif lain pengolahan buah tomat (Yuliani dkk. 2018). Produk ini menyerupai permen, dibuat dari bubur tomat dengan penambahan gula dan bahan penbentuk gell dan dikeringkan. Gula dan bahan pembentuk gell merupakan bahan tambahan yang berpengaruh pada sifat fisik, sifat kimia dan sifat organoleptik permen jelly tomat. Gula yang digunakan biasa sukrosa atau glukosa. Bahan pembentuk gel bisa berupa agar-agar, gelatin atau serbuk jelly. Penggunaan jenis gula dan bahan pembentuk gel yang berbeda akan menghasilkan sifat permen jelly tomat yang berbeda pula. 


\section{METODE}

\section{A. Bahan Penelitian}

Bahan penelitian yang digunakan adalah tomat buah dan bahan tambahan lain seperti gula dan serbuk jely dibeli di pasar Sukoharjo. Bahan kimia yang digunakan antara lain lodium

\section{B. Jalannnya Penelitian}

\section{Pembuatan Jelly Tomat}

Pembuatan saos tomat dilakukan sebagai berikut :

Buah tomat sebanyak $1 \mathrm{~kg}$ dicuci bersih, kemudian dimasukkan dalam air mendidih selama 5 menit. Kemudian buah tomat dihancurkan dengan blender dan disaring. Bubur buah dimasak dengan api kecil dan ditambahkan gula $400 \mathrm{~g}$ dan bahan pembentuk gel $30 \mathrm{~g}$. Pemasakan dilakukan selama kurang lebih 15 menit. Setelah masak dan tercampur rata kemudian dilakukan pencetakan dan didinginkan. Jelly yang telah dingin dikeringkan pada suhu $60-70{ }^{\circ} \mathrm{C}$ sampai tidak lengket. Jelly yang telah kering dikemas dalam stoples.

\section{Variasi Perlakuan}

Perlakuan pada penelitian ini adalah variasi jumlah jenis gula (glukosa, dekstrosa dan sukrosa) serta jenis bahan pembentuk gel (agar-agar dan serbuk jelly)

\section{Analisa yang dilakukan}

a. Pengukuran kadar air dengan metode penguapan (Slamet Sudarmadji, 2019)

b. Pengukuran kadar gula reduksi dengan spektrootometri (Slamet Sudarmadji, 2019)

c. Uji organoleptik meliputi rasa dan kesukaan dengan metode skoring terhadap kesukaan konsumen (Kartiko, B. 1988)

\section{Rancangan Percobaan}

Rancangan percobaan yang digunakan adalah Rancangan Faktorial dengan variasi perlakuan jenis gula dan jenis bahan pembentuk gel.

\section{Analisa Data}

Data yang dihasilkan dianalisis menggunakan software SPSS 17.

\section{HASIL DAN PEMBAHASAN}

\section{A. Produk permen jelly tomat}

Permen jelly tomat pada penelitian ini dibuat dengan variasi jenis gula menggunakan glukosa, dekstrosa, sukrosa dan variasi bahan pembentuk gel menggunakan agar-agar dan bubuk jelly. Permen yang dihasilkan dapat dilihat pada Gambar 5.1.

Secara visual kenampakan permen jelly tomat tidak terlalu berbeda di antara berbabagai variasi, sedikit perbedaan warna yang agak gelap ditemukan pada penggunaan jenis gula dekstrosa.

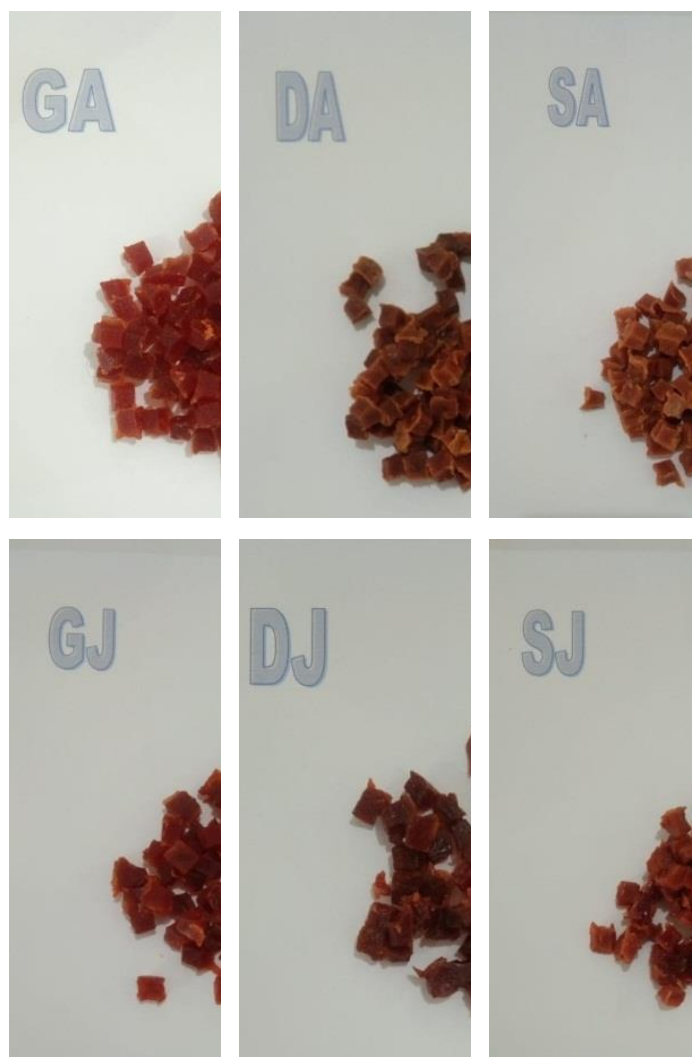

Ket : GA : Glukosa Agar, DA : Dekstrosa Agar, SA : Sukrosa Agar, GJ : Glukosa Jelly, DJ : Dekstrosa Jelly dan SJ : Sukrosa Jelly

Gambar 1 Permen Jelly Tomat dengan Variasi Jenis Gula dan Bahan Pembentuk

Gel 


\section{B. Kadar Air}

Kadar air permen jelly tomat merupakan salah satu indikator kualitas permen jelly tomat. Pada penelitian kadar air permen jelly disajikan pada Gambar 2.

Kadar air permen jelly tomat pada penelitian ini berkisar antara 7,4-10.03 dan tidak memperlihatkan beda nyata di antara semua perlakuan. Dalam SNI kadat air permen jelly maksimal adalah $20 \%$, sehingga pada penelitian ini permen jelly yang dihasilkan terlalu kering. Hal ini didukung juga dengan penelitian lain yang menyatakan bahwa kadar air permen jelly tomat yaitu 16, 2\% (Sinurat, 2014) dan 10,19 \% (Shabrina, 2016).

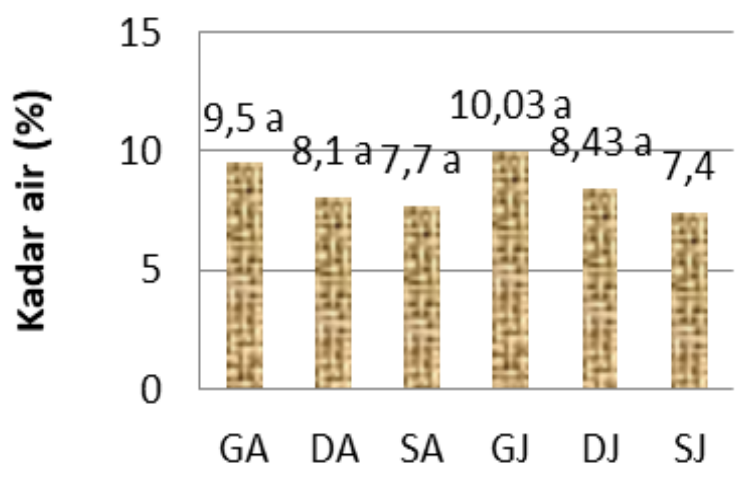

Gambar 2. Kadar Air Permen Jelly Tomat

\section{Kadar Gula Reduksi Permen Jelly Tomat}

Pada penelitian ini gula yang diukur adalah gula reduksi. Kadar gula reduksi pada permen jelly disajikan dalam Gambar 3.

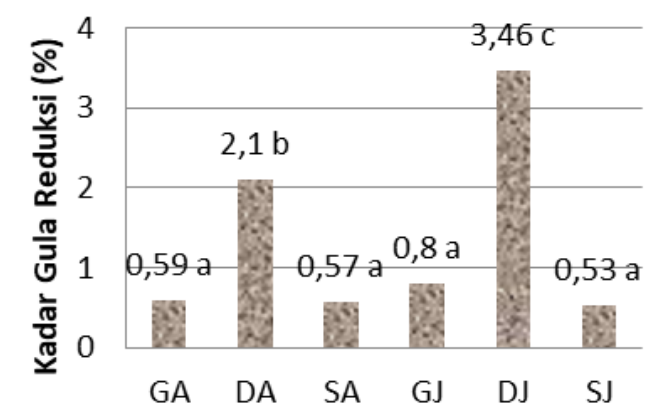

Gambar 3. Kadar Gula Reduksi Permen Jelly Tomat
Gula reduksi pada penelitian ini berkisar antara 0,59-3,46\%. Di antara perlakuan terdapat beda nyata antara permen jelly yang dibuat dengan glukosa dan sukrosa dibandingkan dengan yang dibuat menggunakan dekstrosa.

\section{Uji Organoleptik}

Uji organoleptik dilakukan dengan metode skoring kesukaan pada sampel tentang rasa dan kesukaan secara menyeluruh. Untuk uji rasa dihunakan skor 1 untuk sangat tidak enak, 2 untuk tidak enak, 3 untuk enak dan 4 untuk sangat enak. Untuk uji kesukaan secara menyeluruh digunakan skor 1 untuk sangat tidak suka, 2 untuk tidak suka, 3 untuk suka dan 4 untuk sangat suka. Panelis yang digunakan sebanyak 20 orang. Hasil uji organoleptik terhadap rasa disajikan pada Gambar 4.

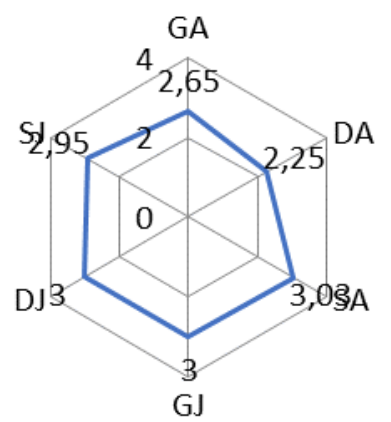

Gambar 4. Uji Organoleptik Rasa

Hasil yang didapatkan dari skor rata-rata adalah permen jelly tomat dengan sukrosa dan agar merupakan permen yang paling disukai dengan skor 3,03 (enak) sedangkan yang menggunakan dekstrosa dan agar merupakan permen yang paling tidak disukai terhadap rasanya dengan skor 2,65 . Terdapat perbedaan yang nyata pada uji statistik pada skor tersebut. Hal ini dapat dimengerti karena sukrosa memberikan rasa manis yang lebih dibandingkan glukosa dan dekstrosa (Mardaweni, P dan Wisudawaty, P. 2018)

Hasil Uji Organoleptik terhadap kesukaan secara menyeluruh disajikan dalam Gambar 5. 


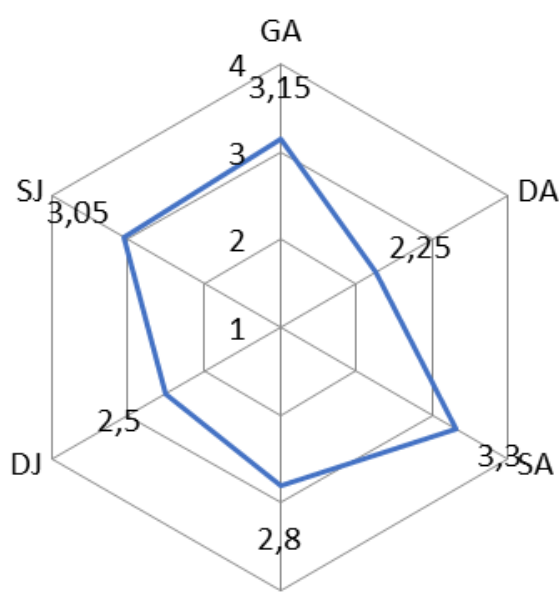

GJ

Gambar 5. Uji Organoleptik Kesukaan

Uji organoleptik terhadap kesukaan secara menyeluruh pada permen dengan dekstosa dan agar merupakan permen yang paling tidak disukai dengan skor 2,25 (tidak suka) dan permen dengan glukosa dan agar merupakan permen yang paling disukai dengan skor 3,03 (suka). Hal ini sangat terkait dengan kenampakan dan kekenyalan permen. Permen yang dibuat dengan dekstrosa memperlihatkan warna yang lebih kusam sedangkan yang dibuat dengan glukosa memperlihatkan kenampakan yang lebih cerah, sedangkan penggunaan agar memperlihatkan kekenyalan yang lebih kokoh dibandingkan dengan bubuk jelly. Hal ini kemungkinan yang menjadi dasar penilaian konsumen.

\section{SIMPULAN}

Dari penelitian yang dilakukan dapat diambil kesimpulan :

1. Kadar air permen jelly tomat dengan berbagai perlakuan berkisar antara 7,4 $10,03 \%$ dan tidak memperlihatkan beda nyata di antara semua perlakuan.

2. Kadar gula reduksi permen jelly tomat berkisar antara 0,59-3,46\%. Di antara perlakuan terdapat beda nyata antara permen jelly yang dibuat dengan glukosa dan sukrosa dibandingkan dengan yang dibuat menggunakan dekstrosa.

3. Permen jelly tomat yang paling disukai terhadap rasa adalah permen yang dibuat menggunakan sukrosa dan agar dan yang paling tidak disukai adalah permen yang dibuat dengan menggunakan dektrosa agar, sedangkan terhadap kesukaan secara menyeluruh yang paling disukai adalah permen yang dibuat menggunakan glukosa agar dan yang paling tidak disukai adalah permen yang dibuat menggunakan dektrosa agar. Kesemuanya memperlihatkan beda nyata.

\section{DAFTAR PUSTAKA}

Buckle, K.A., R. A. Edwards, G. H. Fleet and Wootton, M. 1987. IImu Pangan. Terjemahan H. Purnomo dan Adiono. UIPress, Jakarta.

Endrah W . 2009. Aspek mutu pengolahan saus tomat Aspek Mutu Pengolahan Saus Tomat.

http://endrah.blogspot.co.id/2009/10/asp

ek-mutu-pengolahan-saus-tomat.html. 19 Jan 2017

Handayani, C.B., Tari, A.I.N., Afriyanti. 2018. Umur Simpan Saos Tomat Pada berbagai Konsentrasi Bahan Pengental. Agrisaintifika Jurnal IImu-ilmu Pertanian 2 (2), 113-122

Kartiko, B.1998. Uji Inderawi, PAU Pangan dan Gizi UGM, Yogyakarta

Mardaweni P., Wisudawaty. P. 2018. Analisis Dan Desain Sistem Produksi Permen Jelly Tomat Menggunakan Edible Coating Dengan Penambahan Vitamin C. Jurnal TrendTech Vol 3 No 1, 2018

Novita, Mega.,Mangimbuludu, Jubhar., Rondonuwu, Fredy.S. 2010. Karakteristik Likopen Sebagai Antioksidan. Prosiding Seminar Sain dan Pendidikan Sains. UKSW 
Agrisaintifika

Sinurat, E., Murniyati Murniyati. 2014. Pengaruh Waktu Dan Suhu Pengeringan Terhadap Kualitas Permen Jeli. https://bbp4b.litbang.kkp.go.id/jurnaljpbkp/index.php/jpbkp/article/view/10 6. Diunduh 20 Oktober 2020

Shabrina, A. 2016. Pengaruh Konsentrasi Tepung Agar-Agar Terhadap Sifat Sensori, Kimia Dan Mikrobiologi Permen Jelly Buah Naga Merah (Hylocereus Polyrhizus) Selama Penyimpanan Pada Suhu Ruang. http://digilib.unila.ac.id/24709/ Diunduh 20 Oktober 2020

Slamet Sudarmadji., Bambang Haryono, Suhardi. 2019 Analisa Bahan Makanan dan Pertanian. Liberty. Yogyakarta
Winarno, F.G. 2004. Kimia Pangan dan Gizi. PT. Gramedia. Jakarta.

Yulianti., Husain Syam., Andi Sukainah. 2018. Pemanfaatan Buah Tomat (Solanum Lycopersium) Sebagai Bahan Tambahan Dalam Pembuatan Permen Jelly. Jurnal Pendidikan Teknologi Pertanian Volume 4 September Suplemen (2018) : S14- S 